\title{
Adsorption Efficiency of Activated Carbon Produced from Corn Cob for the Removal of Cadmium Ions from Aqueous Solution
}

\author{
Ezeh Ernest* \\ Chemial Engineering Department, Nnamdi Azikiwe University, Awka \\ Okeke Onyeka \\ Plastic Production Unit, Scientific Equipment Development Institute, Enugu
}

Aburu C. M.

Machine Shop Unit, Scientific Equipment Development Institute, Enugu

Aniobi C. C.

Dept. of Community Medicine, University of Nigeria, Enugu Campus, Enugu

Ndubuisi J. 0.

Applied Science Dept., Federal College of Dental Technology and Therapy, Enugu

\begin{abstract}
Studies were carried out to evaluate the adsorption efficiency of activated carbon produced from corn cob for the removal of $\mathrm{Cd}$ II ions from aqueous solution. The studies were carried out with due consideration of standard analytical procedures and instrumentation. Increase in the Cd II ions concentration from 90 to $180 \mathrm{mg} / \mathrm{l}$ decreased the adsorption capacity of the adsorbent from 89.273 to $65.770 \%$. Increase in the adsorbent's dosage from 0.5 to $2.0 \mathrm{~g}$ increased the adsorption of $\mathrm{Cd}$ II ions from 81.522 to $91.980 \%$. At $\mathrm{pH}$ of 5.0, the adsorption process attained equilibrium with a peak adsorption of $\mathrm{Cd}$ II ion at $93.628 \%$. At a contact of time of $30 \mathrm{mins}$ between the adsorbate (Cd II ions) at the adsorbent; the adsorption of Cd II ions reached a peak value of $92.410 \%$. The adsorption of Cd II ions on the surface of the activated carbon increased from 90.436 to $93.210 \%$ with increase in temperature from $40^{\circ}$ to $160^{\circ} \mathrm{C}$. The decrease in Gibb's free energy of adsorption of Cd II ions on the surface of the activated carbon revealed that the adsorption was favourable at high temperatures. The positive values of $\Delta \mathrm{H}$ and $\Delta \mathrm{S}$ shows that the adsorption process was endothermic.
\end{abstract}

Keywords: Corn cobs; Adsorption efficiency; Aqueous solution; Cadmium ion; and Activated carbon.

(9) (1) CC BY: Creative Commons Attribution License 4.0

\section{Introduction}

Water pollution by heavy metals is considered a serious environmental problem due to their toxicity, long persistence, bioaccumulation and biomagnifications in the food chain [1]. Nowadays water pollution by heavy metals is fast growing due to natural processes and increasing human activities which include mining, agriculture and manufacturing industries. Heavy metals are toxic pollutants released into the surface and ground water bodies as a result of different activities [2]. Heavy metals are non-biodegradable and cannot be detoxified biologically [3]. Environmental pollution by heavy metals is a serious and complex problem that all the time occupies worldwide attention.

Industrial and municipal waste water frequently contains metal ions that can be harmful to aquatic life and human health.

Waste waters containing metal ions such as cadmium, zinc and lead are introduced into water bodies commonly because these metals are widely used and exposure of human beings to these toxic metals even at very low concentrations could results to severe symptoms [1].

Such symptoms include memory loss, increased allergic reactions, high blood pressure, depression, irritability, poor concentration, sleep disabilities, speech disorders, cholesterol, vascular occlusion, neuropathy, autoimmune diseases and chronic fatigue. The effects of acute cadmium poisoning in humans are high blood pressure, kidney damage and destruction of testicular tissue and red blood cells. The treatment methods for metal bearing effluents commonly include chemical precipitation, membrane filtration, electrolytic reduction, solvent extraction, ion exchange and adsorption [4].

Among these treatments, adsorption is considered to be an effective and economical method that has attracted considerable interest.

Adsorption with selection of suitable adsorbent can be an effective and versatile method and can be easily adopted in low cost to remove heavy metals from large amount of industrial waste waters. Activated carbons are adsorbents that are used industrially in multiple processes for product separation and purification and for the treatment of liquid and gaseous effluents [5]. 
Considering, however the high cost of activated carbon and the tedious procedures for its preparation and regeneration, there is a continuing search for low-cost potential adsorbents. The search for low cost and easily available adsorbents has led to the investigation of materials of agricultural and biological origin, alongside those of industrial by-products as adsorbents for removal of heavy-metals [2].

Ligno-cellulosic materials and wastes such as pea nut skin, cotton, onion skin, rice hull, maize stalks, bark, jute fibres, bargasse, rice straw, corn cobs and palm kernel husks have received much attention in the area of heavy metal ion removal [6]. Various functional groups such as carboxylates, phenolic and aliphatic hydroxyls and carbonyl groups in these materials have the ability to adsorb metal ions. Adsorption of heavy metals on the surface of activated carbon materials is one of the most popular methods of removal of metal ions from aqueous solutions. Adsorption is a surface phenomenon in which molecules of the adsorbate (metal ions) are attracted and held to the surface of an adsorbent (activated carbon) until a equilibrium is attained between adsorbed molecules and those still freely distributed in the carrying gas or liquid [7].

Activated carbon is a common term uses to describe carbon-based materials which contain well developed internal pore structure. The microspores of activated carbon provide an excellent condition for adsorption to occur, since the adsorbing material can interact with many surfaces simultaneously [8].

In general, there are three main steps in pollutant sorption onto a solid solvent: the transport of pollutant from the bulk solution to the sorbent surface, adsorption on the particle surface and transport within the sorbent particles [9].

Adsorption studies, in particular kinetics and isotherms, provide information on the mechanism of sorption: that is how the pollutant bounds within the sorbent. The application of corn cob as a biosorbent material present showing potential due to its main components of cellulose, pectin, hemicelluloses and lignin which contain functional groups as binding sides for metals [10].

Therefore studies were conducted to evaluate the adsorption efficiency of activated carbon produced from corn cob for the removal of cadmium ions aqueous solution.

\section{Materials and Methods \\ 2.1. Preparation of the Biomass}

The corn cob samples were collected from farms and markets within Enugu metropolis, Enugu, Nigeria. This material is a zero value agricultural waste product. It was washed thoroughly with water and sun dried for 5 days. The dried biomass was milled and sieved using $100-300 \mu \mathrm{m}$ analytical sieves. The sieved materials were subsequently washed with $0.01 \mathrm{M} \mathrm{HCl}$ in order to remove any interfering substances that might be in the biomass.

\subsection{Preparation of Activated Carbon} [12].

The activated carbon was prepared according to the reported procedures of El-Nemr, et al. [11], Esmaelli, et al.

The corn cob powder (200g) was weighed into a clean dry beaker containing $200 \mathrm{ml}$ of $95 \% \mathrm{H}_{2} \mathrm{SO}_{4}$ for about $24 \mathrm{hrs}$ and was followed by refluxing in a fume hood for $4 \mathrm{hrs}$.

After cooling, the reaction mixture was filtered with distilled water and soaked in $1 \% \mathrm{NaHCO}_{3}$ solution to neutralize any remaining acid. The sample was then washed with distilled water until a neutral pH between 6 and 7 was obtained. The sample were then dried overnight in an oven at $150^{\circ} \mathrm{C}$ and kept in a glass bottle until use.

\subsection{Adsorbate}

A stock solution of $1000 \mathrm{mg} / \mathrm{l} \mathrm{Cd}$ II ions was prepared by dissolving $\mathrm{CdCl}_{2}$ (Merck, South Africa) in ultra pure water (resistivity $>18 \mathrm{M} \Omega \mathrm{Cm}^{-1}$ ) and acidified with $5 \mathrm{ml}$ of concentrated $\mathrm{HNO}_{3}$ to prevent hydrolysis.

Progressive dilution procedure of the stock solution was employed in the preparation of the working solutions. The $\mathrm{pH}$ of the working solutions was adjusted to required values with $0.1 \mathrm{M} \mathrm{NaOH}$ or $0.1 \mathrm{M} \mathrm{HCl}$. All the chemicals used were of analytical reagent grade.

\section{Batch Adsorption Studies}

A weighed amount of activated carbon was introduced into the stoppered reagent bottles of various concentrations with $100 \mathrm{ml}$ aqueous solutions of $\mathrm{Cd}$ II ions. The suspensions were shaken at room temperature using a mechanical shaker for a prescribed time at 160rpm. The solutions were filtered using whatmann 42 filter paper and the residual concentrations of metal ion determined by flame atomic absorption spectrophotometer at $210 \mathrm{~nm}$.

The effects of concentration $(90-180 \mathrm{mg} / \mathrm{l})$, adsorption dose $(0.5-2.0 \mathrm{~g})$, solution $\mathrm{pH}(2.5-9.0)$ contact time $(10$ $-40 \mathrm{~min})$ and temperature $\left(40-160^{\circ} \mathrm{C}\right)$ were studied.

Blank solutions were treated similarly and the recorded concentration at the end of each procedure was taken as the initial one.

The percentage of removed Cd II ions (R\%) in solution was calculated using;

$R \%=\frac{C_{O}-C_{e}}{C_{O}} \times \frac{100}{1}$

Where Co is the initial concentration of the metal ion while Ce is the equilibrium concentration of the metal ion. Calculation of thermodynamic parameters 
The values of $\Delta \mathrm{H}$ and $\Delta \mathrm{S}$ wave calculated from the slope and intercept of the linear Van't Hoff plot respectively, using the relation;

$$
\operatorname{LnKd}=\frac{\Delta S}{R}-\frac{\Delta H}{R T}
$$

Where $\Delta \mathrm{S}=$ entropy change for the process,

$\Delta \mathrm{H}=$ enthalpy change for the process,

$\mathrm{R}=$ gas constant and $\mathrm{T}=$ absolute temperature.

The distribution coefficient $(\mathrm{Kd})$ on the activated carbon surface were calculated using the equation;

$K d=\frac{C_{O}-C_{e}}{C_{O}} \times \frac{V}{M}(m g / l)$

The changes in free energy $(\Delta \mathrm{G})$ for the specific adsorption were calculated using the equation;

$\Delta \mathrm{G}=-\mathrm{RT}$ LnKd

Where the symbols have their usual significance.

\subsection{Results and Discussion}

Effect of concentration

Table 1 shows that as the concentration of the adsorbate (Cd II ions) were increased from 90 to $180 \mathrm{mg} / \mathrm{l}$, the adsorption efficiency of the adsorbent decreased from 89.27 to $65.77 \%$.

\begin{tabular}{|c|c|c|c|}
\hline Concentration (mg/l) & Co & $\mathrm{Ce}$ & $R \%=\frac{C_{O}-C_{e}}{C_{O}} \quad X \frac{100}{1}$ \\
\hline 90 & 88.105 & 9.450 & 89.270 \\
\hline 120 & 30.916 & 7.204 & 76.701 \\
\hline 150 & 8.412 & 2483 & 70.484 \\
\hline 180 & 2.682 & 0.918 & 65.773 \\
\hline
\end{tabular}

This observed behaviour can be attributed to the increase in the amount of Cd II ions to the unchanging number of available active sites in the adsorbent.

Fig I. shows a graphical decline in the percentage adsorption efficiency of the absorbent as the concentration of the Cd II ions were increased.

Fig-I. A graphical representation of adsorption efficiency of activated carbon at varying concentrations of the adsorbate

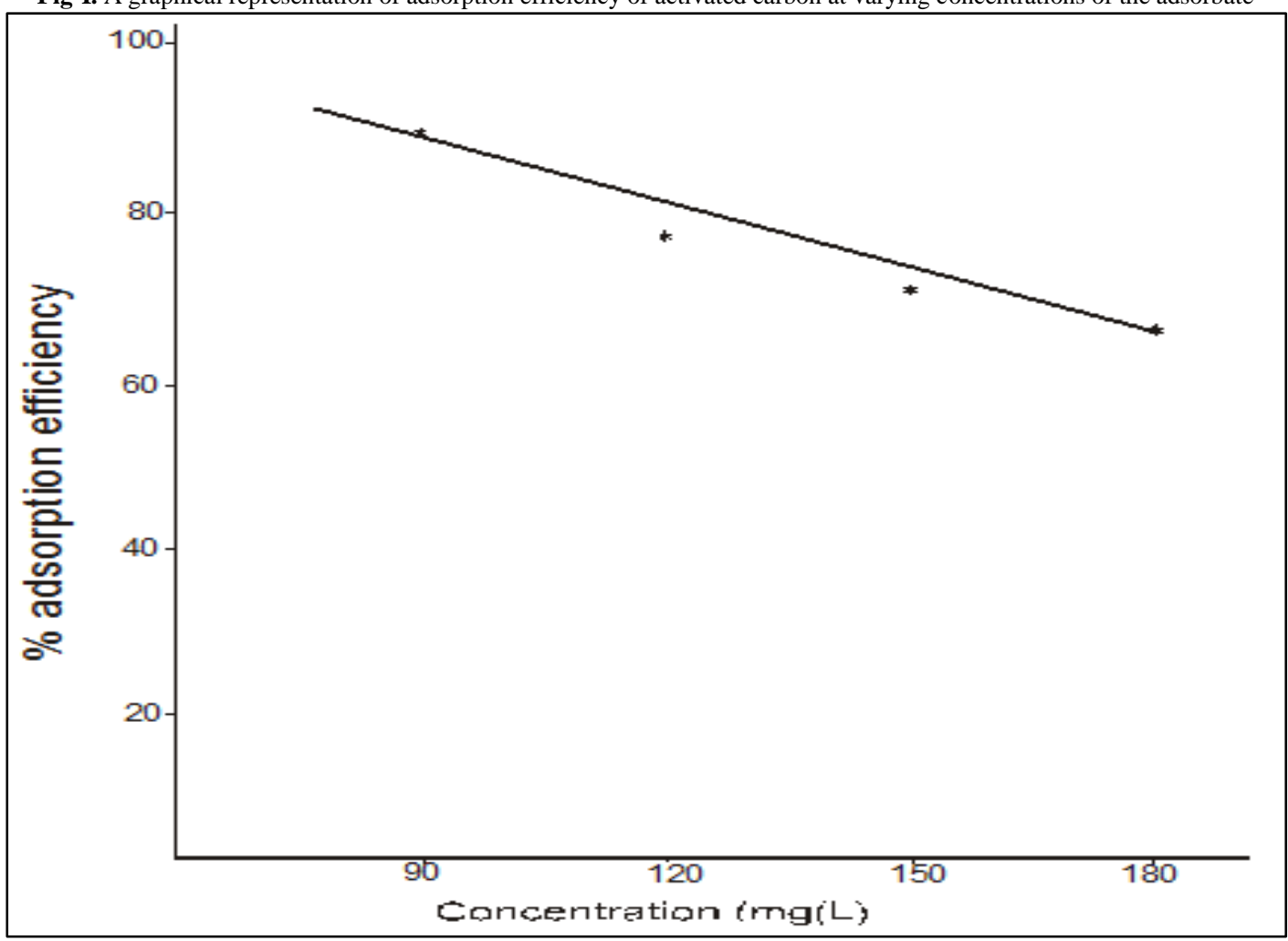

The findings of this study agreed with the report made by Moyo, et al. [13] who observed a decrease in adsorption efficiency of activated carbon from $70 \%$ to $52 \%$ for $\mathrm{Pb}$ II ions in aqueous solution. The study implies that the adsorption efficiency of Cd II ions by the activated carbon is concentration dependent. 


\subsection{Effect of Dosage}

Table 2 shows that as the adsorbent dosage were increased from 0.5 to $2.0 \mathrm{~g}$ in the aqueous solution, the adsorption efficiency or removal efficiency of the adsorbent was found to increase from 81.52 to $91.98 \%$. Therefore increase in the adsorbent's dosage significantly increased the removal of Cd II ions in the aqueous solution.

Table-2. Percentage adsorption efficiency of activated carbon at different dosages

\begin{tabular}{l|l|l|l}
\hline Dosage (g) & Co (mg/l) & Ce (mg/l) & $R \%=\frac{C_{O}-C_{e}}{C_{O}} \times \frac{100}{1}$ \\
\hline 0.5 & 88.105 & 16.280 & 81.522 \\
\hline 1.0 & 88.105 & 12.842 & 88.424 \\
\hline 1.5 & 88.105 & 10.393 & 88.204 \\
\hline 2.0 & 88.105 & 7.069 & 91.980 \\
\hline
\end{tabular}

Fig-2. Shows an increase in the percentage removal of Cd II ions in the aqueous solution as the adsorbent dosage was increased.

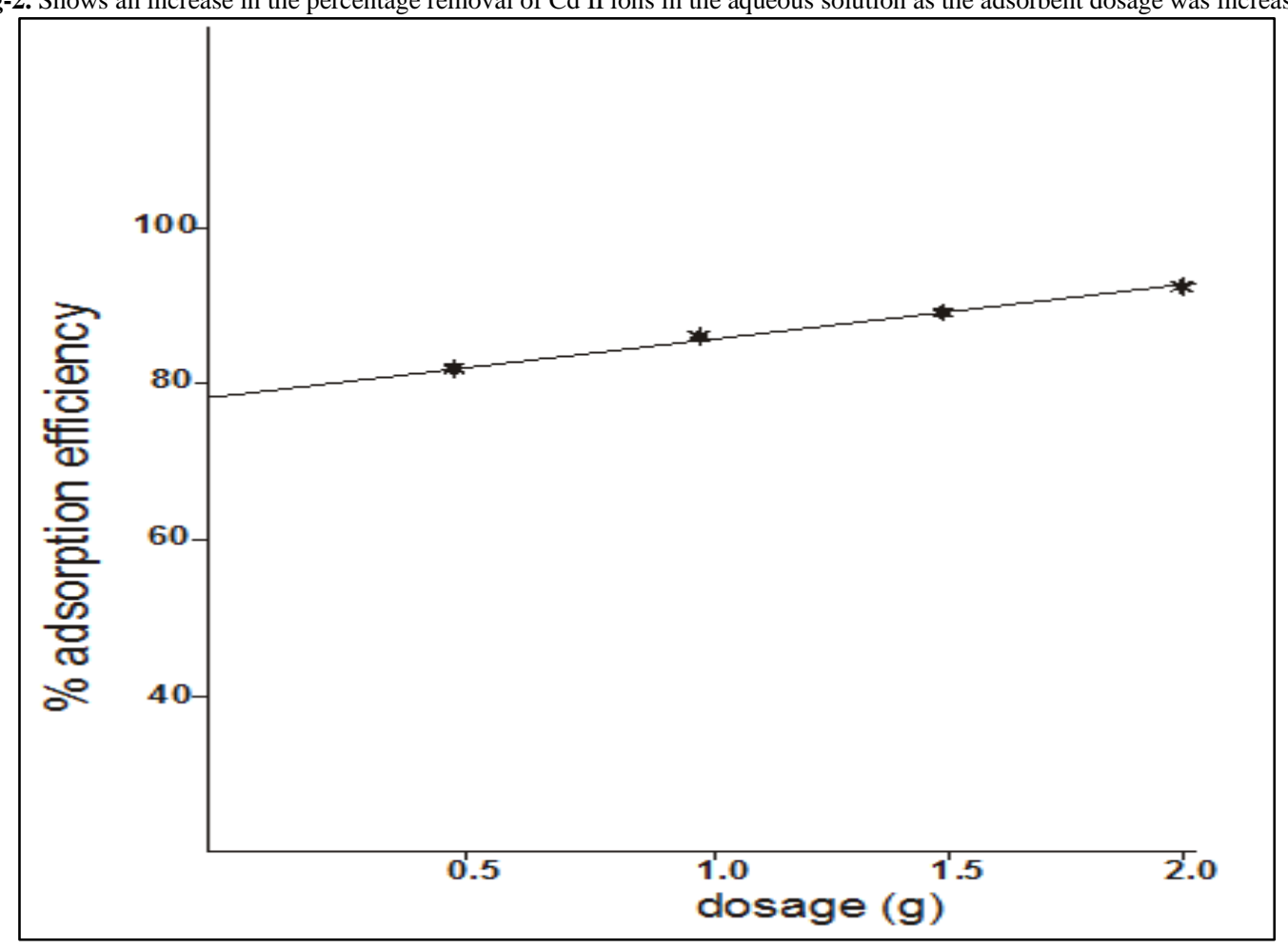

Fig. 2 A graphical representation of adsorption efficiency of activated carbon at varying adsorbent dosages

This phenomenon can be attributed to the greater availability of active sites or surface area, thus enabling faster and easier penetration of the heavy metal onto the adsorption sites of the adsorbent.

The result of this study compares favourably with the findings of Esposito, et al. [14] in which they reported that higher dosage of adsorbent in aqueous metallic solutions increases adsorption due to more surface areas and functional groups being available on the adsorbent.

Ali, et al. [15], observed an increase in removal efficiency of activated carbon for heavy metal (Ni II ion) in aqueous solution from 40 to $80 \%$ and this agreed with what was reported in this study.

\subsection{Effect of $\mathrm{pH}$}

The $\mathrm{pH}$ is one of the most imperative factors governing the adsorption of metal ions in aqueous solutions which affects the functional groups protonation and also metal ion adsorption by the adsorbents.

Table-3. Percentage adsorption efficiency of activated carbon at varying $\mathrm{pH}$

\begin{tabular}{l|l|l|l}
\hline $\mathbf{p H}(\mathbf{g})$ & $\mathbf{C o}$ & $\mathbf{C e}$ & $R \%=\frac{C_{O}-C_{e}}{C_{O}} \times \frac{100}{1}$ \\
\hline 2.5 & 88.105 & 6.716 & 92.377 \\
\hline 5.0 & 88.105 & 5.814 & 93.628 \\
\hline 7.5 & 88.105 & 7.193 & 91.840 \\
\hline 9.0 & 88.105 & 7.022 & 92.030 \\
\hline
\end{tabular}

The effect of $\mathrm{pH}$ in an aqueous solution for the adsorption of metal ions is a major factor used in determining the adsorption property of an adsorbent in aqueous solution. 
Table 3 shows that as the aqueous solution was made less acidic from 2.5 to 5.0 the adsorption efficiency increased from 92.377 to $93.628 \%$. At $\mathrm{pH}$ of 5.0, the adsorbent adsorbed $\mathrm{Cd}$ II ions to the highest value and was equally the equilibrium $\mathrm{pH}$ for the maximum $\mathrm{Cd}$ II ions adsorption by the adsorbent.

The adsorption efficiency of $\mathrm{Cd}$ II ion by the activated carbon was lowest at aqueous solution $\mathrm{pH}$ of 7.5 which could be due to the electrostatic repulsion forces between the positively charged $\mathrm{H}_{3} \mathrm{O}^{+}$and $\mathrm{Cd}^{2+}$ ions.

In comparison, the percentage removal of $\mathrm{Cd}$ II ions decreases in the alkali medium perhaps due to the formation of $\mathrm{Cd}(\mathrm{OH})_{2}$ and soluble hydroxyl complexes $\mathrm{CdOH}^{+}$and $\mathrm{Cd}(\mathrm{OH})^{3-}$ which could deteriorates the adsorption efficiency of the adsorbent.

Fig-3. A graphical representation of adsorption efficiency of activated carbon at varying $\mathrm{pH}$

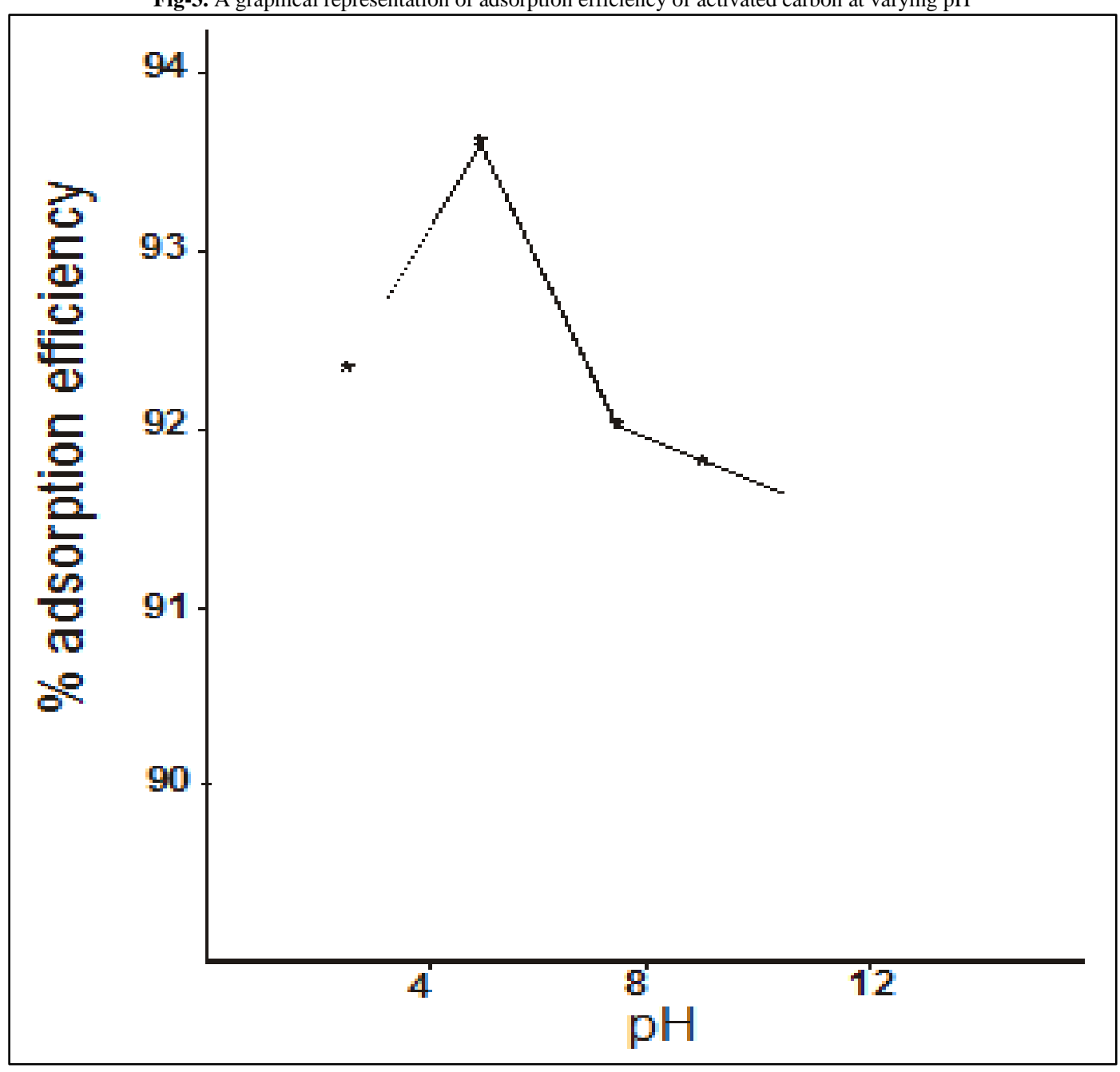

The results of this study on the effect of $\mathrm{pH}$ on the adsorption efficiency of activated carbon agreed with the findings of Mengistie, et al. [2] who reported an increase in adsorption efficiency of activated carbon for Pb II ions in aqueous solution as it was made less acidic.

\subsection{Effect of Contact Time}

Table-4. Percentage adsorption efficiency of activated carbon at varying contact time

\begin{tabular}{l|l|l|l}
\hline Time (min) & Co & Ce & $R \%=\frac{C_{O}-C_{e}}{C_{O}} \times \frac{100}{1}$ \\
\hline 10 & & & \\
\hline 20 & 88.105 & 11.704 & 86.715 \\
\hline 30 & 88.105 & 9.062 & 89.532 \\
\hline 40 & 88.105 & 6.864 & 92.410 \\
\hline
\end{tabular}

Table 4 shows that by varying the contact time of the adsorbent and the adsorbate in the aqueous solution from 10 to 30 minutes, the percentage adsorption of Cd II ions by the adsorbent increased from 86.715 to $92.410 \%$ while at 40 minutes contact time, there was a decrease in the adsorption efficiency to $90.981 \%$.

The table further shows that the adsorption capacity of the adsorbent reached equilibrium at a contact time of 30 minutes during which adsorption efficiency peaked at $92.410 \%$ after which a decline in adsorption of Cd II ion was observed (Fig. 4). 
Fig-4. A graphical representation of adsorption efficiency of activated carbon at varying contact time

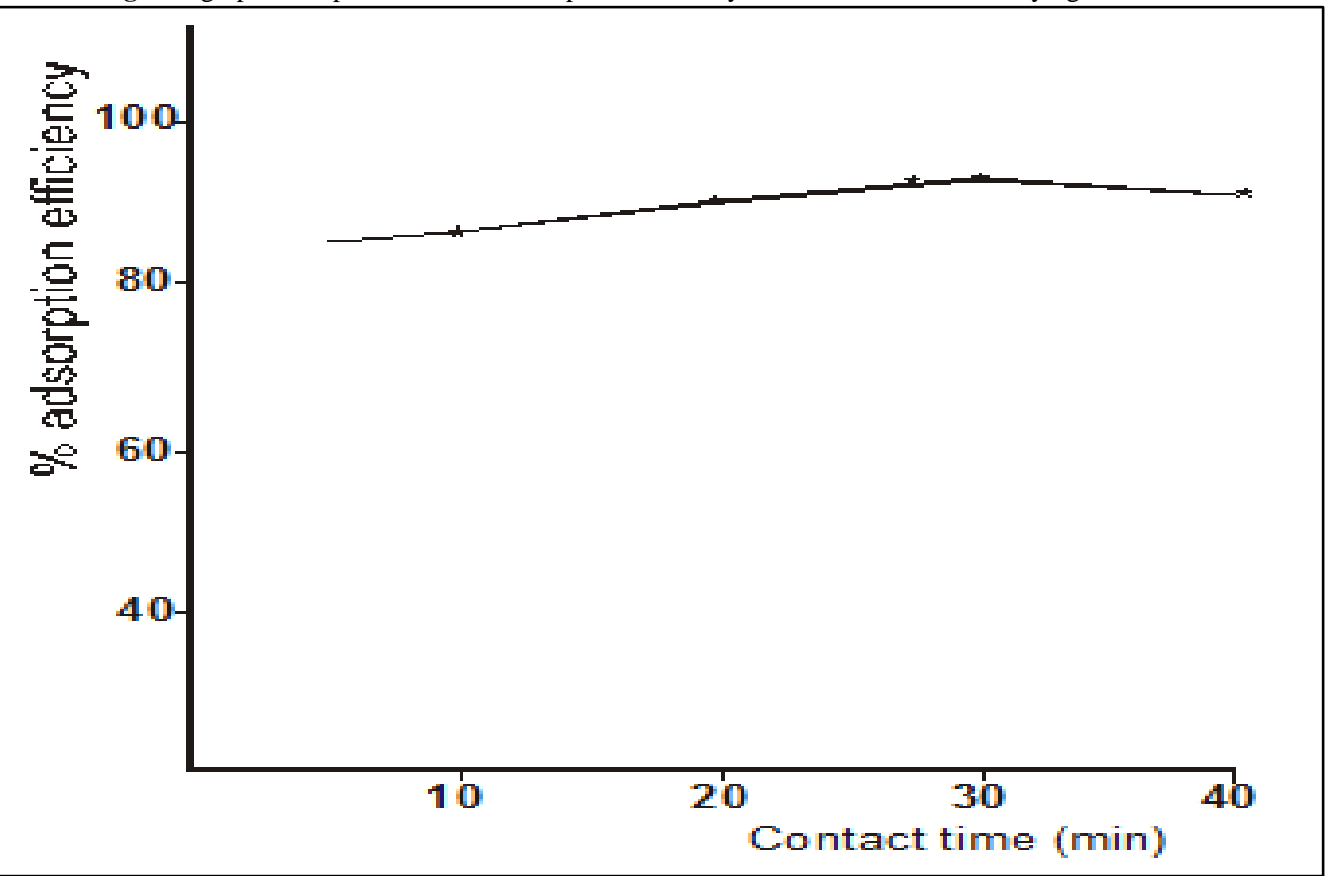

The presence of adequate external surface area on the activated carbon may have boosted the rate of adsorption in the initial stages (10 to 30 minutes), which was followed by slower internal diffusion process as shown in Fig. 4.

Table-5. Kinetic of adsorption at varying contact time

\begin{tabular}{l|l|l|l}
\hline Time (mm) & Co & Ce & Ln Co/Ce \\
\hline 10 & 88.105 & 11.704 & 2.019 \\
\hline 20 & 88.105 & 9.062 & 2.275 \\
\hline 30 & 88.105 & 6.864 & 2.550 \\
\hline 40 & 88.105 & 7.999 & 2.403 \\
\hline
\end{tabular}

The reaction kinetics of adsorption of $\mathrm{Cd}$ II ions on the surface of the activated carbon at varying contact time was of the first order following a plot of $\mathrm{LnCo} / \mathrm{Ce}$ against contact time as shown in Fig 5.

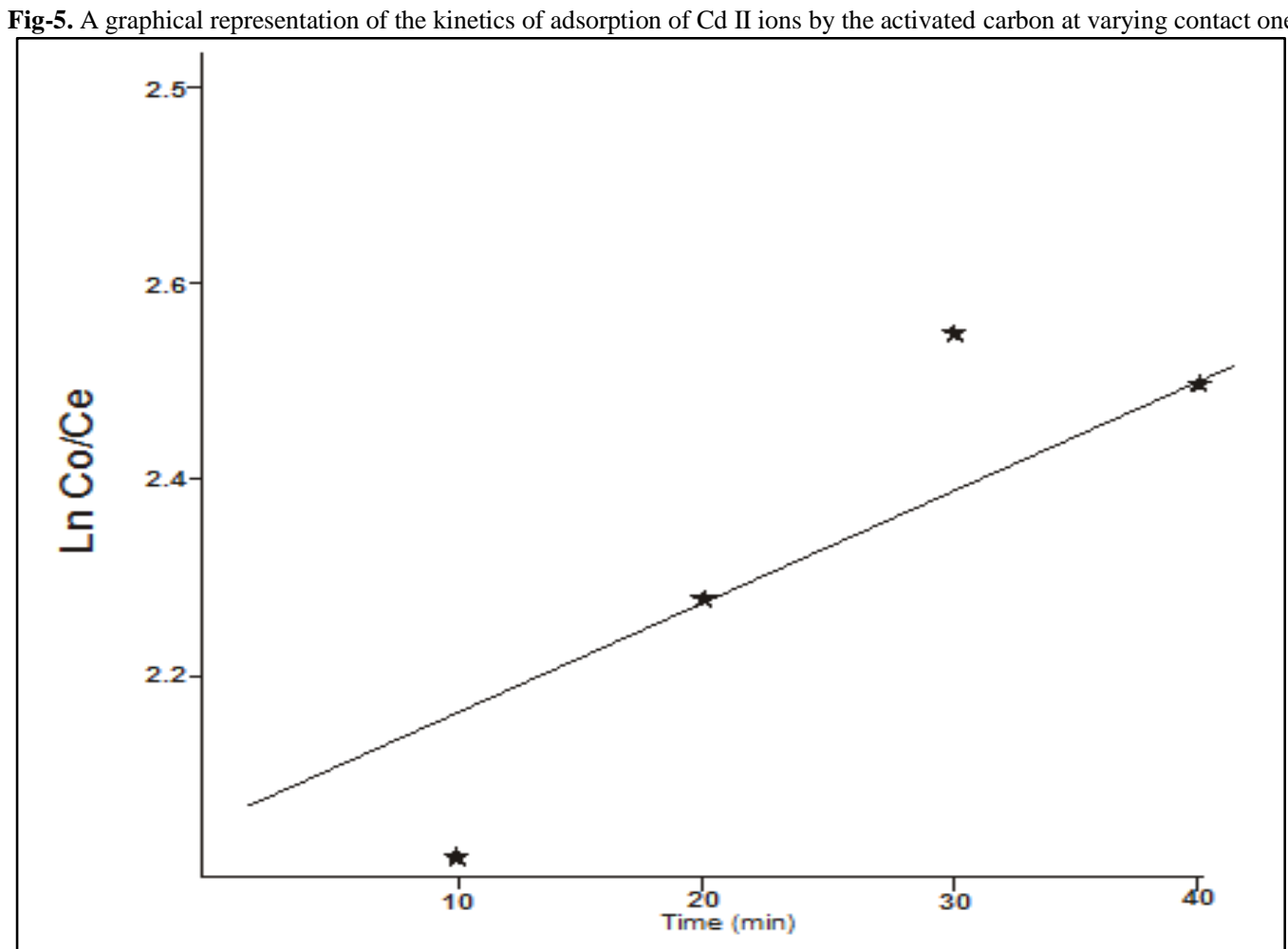

The plot shows a straight-line graph confirming that the adsorption kinetic of the Cd II ions on the surface of the activated carbon at varying contact time was of the first order. 
Therefore, the study of adsorption kinetics describes the solute uptake and evidently this rate control the residence time of adsorbate intake at the solid solution interface.

\subsection{Effect of Temperature}

Table-6. Percentage adsorption efficiency of activated carbon at varying temperature

\begin{tabular}{l|l|l|l}
\hline Temp ${ }^{\mathbf{O}} \mathbf{C}$ & $\mathbf{C o}$ & $\mathbf{C e}$ & $R \%=\frac{C_{O}-C_{e}}{C_{O}} \times \frac{100}{1}$ \\
\hline 20 & & & \\
\hline 40 & 88.105 & 8.426 & 90436 \\
\hline 60 & 88.105 & 7.102 & 91.940 \\
\hline 80 & 88.105 & 6.422 & 92.711 \\
\hline
\end{tabular}

Table 6 shows that increase in temperature of the reaction from 40 to $160^{\circ} \mathrm{C}$ increased the adsorption efficiency of activated carbon for Cd II ions in the aqueous solution from 90.436 to $93.210 \%$.

The extent of adsorption of Cd II ions by the activated carbon at various temperature have been shown in Fig. 6 .

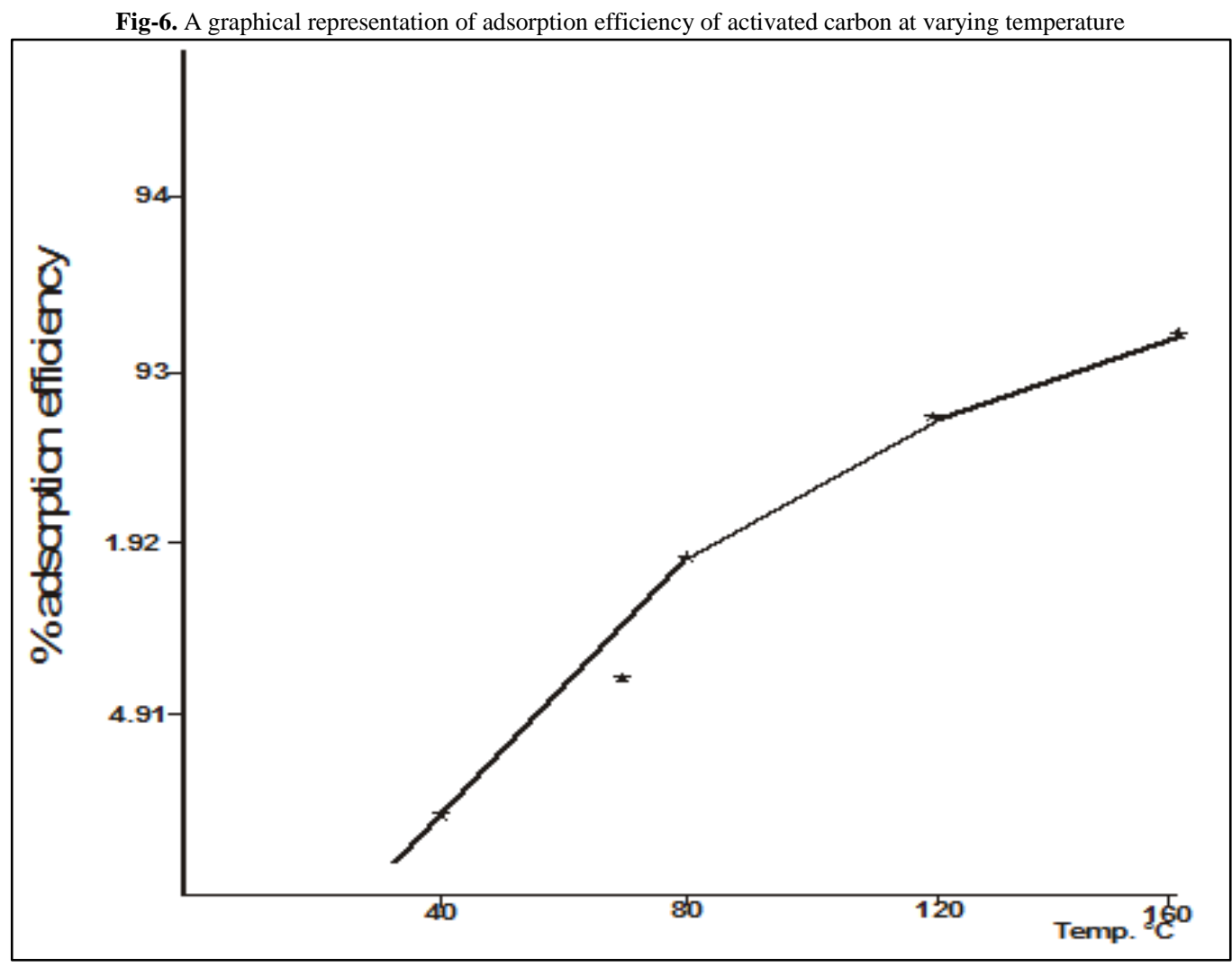

This result shows that as the temperature of the reaction was increased the adsorption efficiency of the adsorbent for the adsorbate in the aqueous solution increased possibly due to increased mobility and diffusion of the ionic species.

Since diffusion is an endothermic process, it would be expected that an increase in solution temperature would result to the enlargement of pore size due to activated diffusion causing the microspores to widen and deepen and create more surfaces for adsorption.

Table-7. Adsorption studies of $\mathrm{Cd}$ II ions on the surface of activated carbon as a function of temperature.

\begin{tabular}{l|l|l|l|l|l|l}
\hline $\mathbf{T}^{\mathbf{0}} \mathbf{K}$ & $\frac{1}{T} \times 10^{-3}\left(K^{-1}\right)$ & $\mathbf{K d}$ & $\mathbf{L n K d}$ & $\Delta \mathbf{H}\left(\mathbf{k j m o l}^{-\mathbf{1}}\right)$ & $\Delta \mathbf{S ~ j m o l}$ & $\Delta \mathbf{G}\left(\mathbf{k j m o l} \mathbf{~}^{-\mathbf{1}}\right)$ \\
\hline 313 & 3.195 & 45.218 & 3.8110 & & & \\
\hline 353 & 2.833 & 46.101 & 3.8310 & & & -9.917 \\
\hline 393 & 2.544 & 46.850 & 3.850 & 4.755 & & -11.243 \\
\hline 433 & 2.309 & 47.221 & 3.864 & & & -12.579 \\
\hline
\end{tabular}

Table 7 shows that the decrease in the $\Delta \mathrm{G}$ values from -9.917 to $-13.910 \mathrm{kjmol}^{-1}$ with increase in temperature from 313 to $433 \mathrm{k}$ reveals that adsorption of Cd II ions on the surface of the adsorbent was favourable at higher temperatures. 
Hence, the negative values of Gibb's free energy of adsorption of Cd II ions indicate that the whole process was spontaneous and therefore increases the affinity of Cd II ions on the adsorbent.

A plot of $\operatorname{lnKd}$ against $1 / \mathrm{T}$ gave a straight line and evaluation of $\Delta \mathrm{S}$ from the plot gave a value of $132.96 \mathrm{jmol}^{-1}$

Fig-7. A graphical representation of adsorption of Cd II ions as a function of temperature

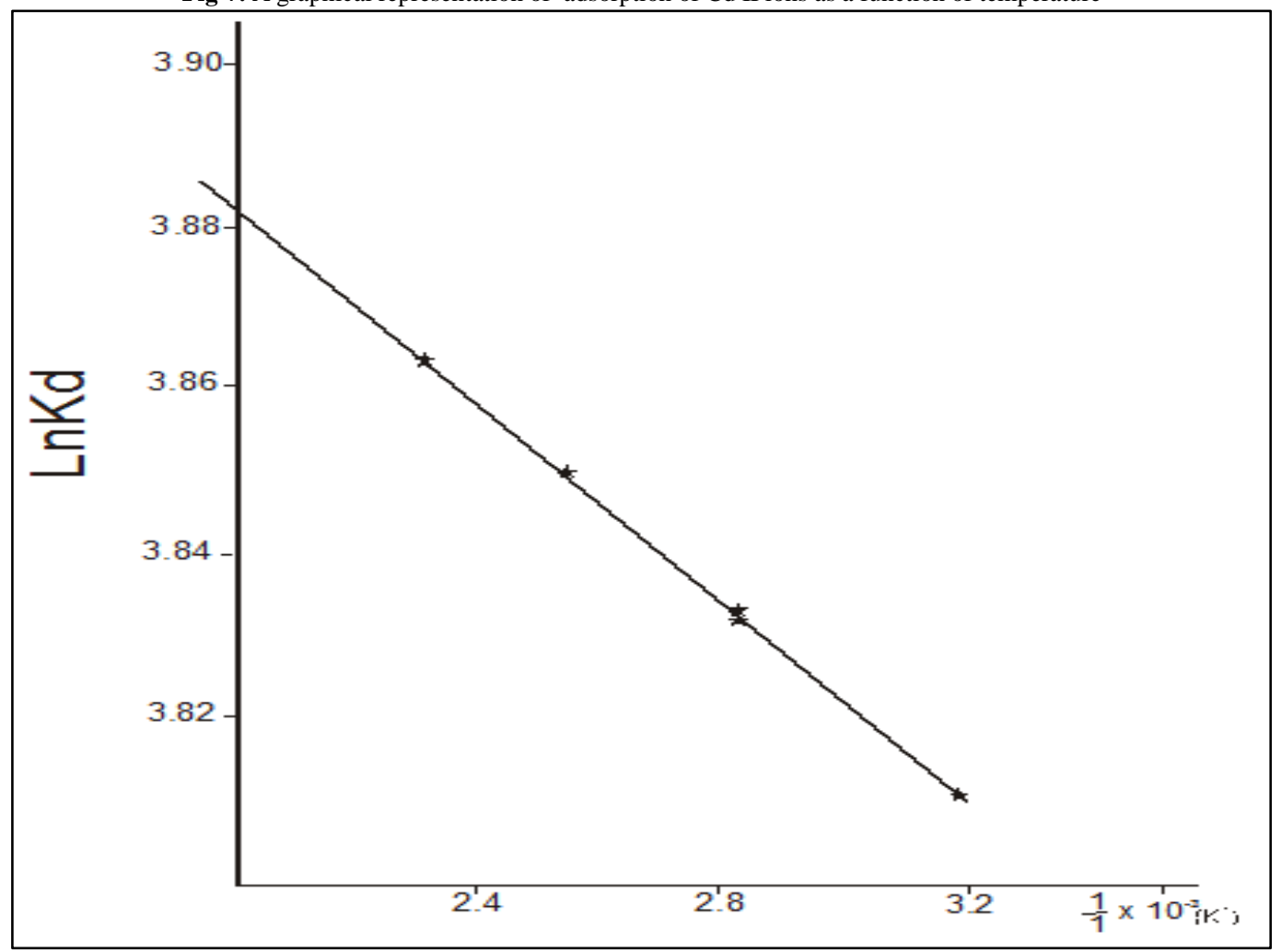

The positive values of $\Delta \mathrm{S}$ reveals an increase in randomness at the solid solution interface during the fixation of $\mathrm{Cd}$ II ions on the active sites of the adsorbent.

The enthalpy of adsorption of Cd II ions estimated from the plot was $14.67 \mathrm{kjmol}^{-1}$

The positive value of the $\Delta \mathrm{H}$ therefore shows that the adsorption of Cd II ions on the surface of the activated carbon was an endothermic process.

\section{Conclusion}

The result of this study clearly demonstrates the potential of using activated carbon from corn cob in the adsorption of heavy metals (Cd II ions) from aqueous solution. Since the removal of heavy metals from waste water or aqueous solution is normally a costly venture for any corporate or private entity, the use of lignocellusic materials such as corn cob, which are wastes in the environment, in the production of activated carbon for the adsorption of organic and inorganic pollutants in aqueous solutions should be supported and given every attention by concerned stakeholders. The study shows that effective adsorption of $\mathrm{Cd}$ II ions on the surface of activated carbon is time, temperature, dosage, concentration and $\mathrm{pH}$ dependent.

\section{References}

[1] Wodjanarovits, L., Foldvary, C. M., and Takacs, E., 2010. "Radiation induced graphing of cellulose for adsorption of hazardous water pollutants." A Fadiation Physics and Chemistry, vol. 79, pp. 848-262.

[2] Mengistie, A. A., Siva, R. T., Piasado, Rao, A. V., and Singanan, M., 2008. "Removal of lead II ions from aqueous solution using activated carbon from militia femiginea plant leaves. Bull Clen. SOC." Ethiopia, vol. 22, pp. 349-360.

[3] Kumar, P. S., 2013. "Adsorption of Lead II ions from simulated waste water using natural waste: a kinetic, thermodynamic and equilibrium study." Environmental Progress and Sustainable Energy, pp. 174-181. Available: https://aiche.onlinelibrary.wiley.com/doi/pdf/10.1002/ep.11750

[4] Davila-Jimenez, M. M., Elizade-Gonzalez, M. P., Geyer, W., Mattusch, J., and Wennrich, R., 2003. "Adsorption of metal cations from aqueous solution onto a national and a model bio composite." Colloids Surf Physico-Chem Eng. Aspects, vol. 219, pp. 243-289.

[5] Manoocheberi, M., Korsand, A., and Hasheni, G., 2012. "Role of modified activated carbon by H3PO4 or $\mathrm{K} 2 \mathrm{CO} 3$ from natural adsorbent for the removal of $\mathrm{Pb}$ II from aqueous solutions." Carbon Letters, vol. 13, pp. $115-120$.

[6] Aharoni, C. and Spark, D. L., 1991. "Kinetics of soil chemical reactions - theoretical treatment, Sverez D.L. Rates of soil chemical processes, soil science of America." Madison, vol. 161, pp. 753-761. 
[7] Radenoviae, A., Malina, J., and Strkaly, A., 2011. "Removal Ni II from aqueous solution by low cost adsorbent." The Holistic Approach to Environment, vol. 13, pp. 109-120.

[8] Cecen, F. and Aktas, O., 2011. Activated carbon for water and waste water treatment, integration adsorption and biological treatment. Weinheim: Wiley - VCH Publishers. pp. 379-394.

[9] Crini, G., 2003. "Recent developments in polysaccharide based materials used as adsorbents in waste water treatment." Polymer Science, vol. 30, pp. 38-70.

[10] Kaushik, C. P., Tuteja, R., Kaoshik, K., and Sharma, J. K., 2009. "Minimization of organic chemical load in direct dyes effluent using low cost adsorbents." Chemical Engineering Journal, vol. 133, pp. 234-240.

[11] El-Nemr, A., Sikaily, A. E., Khaled, A., and Abdelwahab, O., 2007. "Removal of toxic chromium VI from aqueous solution by activated carbon using Casuarina equisetifolia." Chemistry and Ecology, vol. 23, pp. 119-129.

[12] Esmaelli, A., Ghasemi, S., and Sohrabipour, I., 2010. "Biosorption of copper from waste water by activated carbon preparation from alga sargassium sp." Natural Product Research, vol. 24, pp. 341-348.

[13] Moyo, M., Chikazaza, L. B., Nyaminda, B. C., and Guyo, U., 2013. "Adsorption batch studies on the removal of $\mathrm{Pb}$ II using maize tassel based activated carbon." International Journal of Physical Science Research, vol. 17, pp. 303-317.

[14] Esposito, A., Ragnanelli, F., Lodi, A., and Veglio, F., 2011. "Biosorption of heavy metals by Sphaerotilus natans an equilibrium study as different $\mathrm{pH}$ and biomoss concentration." Journal Hydrometallurgy, vol. 60 , pp. 129-141.

[15] Ali, H. H., Pmal, M. A., and Hussaini, A. M., 2017. "Removal of some heavy metals from aqueous solution using natural wastes from orange peel activated carbon." IJRDO Journal of Applied Science, vol. 3, pp. 1326 